\title{
Mapping Biopharmaceutical Innovation and Diffusion: How the Second Translational Block (T2) Shapes Drug Diffusion
}

\author{
Joshua Cohen", Laura Faden and Kenneth Getz
}

Tufts Center for the Study of Drug Development (CSDD), Tufts University School of Medicine, USA

\begin{abstract}
In the US, there is a vigorous public debate on the merits of biopharmaceutical innovations and their diffusion. There is virtual unanimity about the importance of maintaining a steady stream of biopharmaceutical innovations, to which patients should have timely access. However, the debate's participants are cognizant that the effects of innovation and diffusion on health outcomes, health care spending, and incentives for future innovation, must be weighed against one another.

First, we performed a Medline literature review to map the innovation diffusion process, combining the search terms "innovation," "diffusion," and "pharmaceutical." Second, we conducted a survey of 190 physicians to examine their valuation of the innovativeness and rate of diffusion of 20 new molecular entities (NMEs). Third, we collected data from the Centers for Medicare and Medicaid Services (CMS) Formulary Finder to assess payers' valuation of the innovativeness of the 20 NMEs in question.

Based on our literature review, we identified the key stakeholders involved in the innovation diffusion process. Furthermore, we highlighted the changing landscape of translational movers and shakers, tracing the emergence of T2 barriers, emanating largely from third party payer formulary management.

Our empirical analysis suggests payers are exerting influence on physicians' prescribing decisions, while the role of patients and pharmaceutical firms has diminished somewhat. Payers directly affect prescribing decisions through the use of formularies, and indirectly by funding evidence-based continuing medical education.

On average, across the 20 drugs we sampled, the time from approval to first prescription was 33 months, which indicates a slow diffusion process. Our data analysis shows a gap in perception of innovativeness between physicians and payers, with physicians ranking drugs as more innovative on average than payers. And, our findings suggest the more innovative a drug is perceived by physicians and payers the higher market share it has.

Striking an appropriate balance on access to and cost of biopharmaceuticals will require policy adjustments on the part of payers. In cases in which there is a large degree of uncertainty or the fiscal impact is particularly high, coverage could be made subject to a policy of coverage with evidence development (CED). Here, coverage would be conditional on development and capture of outcome data. A CED policy could be combined with a risk-sharing arrangement in which financial risk is shared between payers and the biopharmaceutical industry.
\end{abstract}

\section{INTRODUCTION}

An innovation is an idea, practice, or object that is perceived as new by a unit of adoption [1].

Diffusion is the process by which an innovation is communicated through certain channels over time and ultimately adopted among the members of a social system [1].

During the past several decades an unprecedented number of biopharmaceuticals have produced significant clinical benefits. Enormous sums of resources from both private and public sources have poured into biopharmaceutical research and development. This, in turn, has lead to a surge in new drug development. New drugs, diagnostic techniques, and surgical procedures have helped millions of patients live longer, better quality lives [2]. At the same time, health

*Address correspondence to this author at the Tufts Center for the Study of Drug Development (CSDD), 75 Kneeland Street, Suite 1100, Boston, Massachusetts 02111, USA; Tel: 617-636-3412; Fax: 617-636-2425;

E-mail: joshua.cohen@tufts.edu economists suggest that technological advance (i.e., innovation) is an important cause of rising expenditures [3]. Tension has arisen between the benefits of innovation and limits to how much innovation health care systems can afford. Faced with scarce resources, third party payers and policymakers must increasingly compare the value of drugs with their effect on spending. To illustrate, since drug innovation is a significant driver of rising health care costs [4], a major challenge for payers is which newly approved drugs to include on formularies, under what kinds of cost sharing arrangements, and with which conditions of reimbursement, such as prior authorization, step therapy, quantity limits, and indication restrictions. Coverage decisions depend primarily on clinical considerations, but increasingly also costeffectiveness. Likewise, physicians and patients are faced with choices on which drugs to utilize. As shared decision makers, physicians and patients must consider numerous factors, including clinical- and cost-effectiveness.

In short, there is a complex institutional interplay involving diverse stakeholders through which biopharmaceutical 
innovations emerge and get diffused [5]. Here, we define diffusion as the translational process - translational block T2 - of bringing a new drug or indication into use in a clinical setting [6]. Stakeholders each seek evidence to guide decisions regarding the evaluation, initial adoption, as well as diffusion of biopharmaceutical innovations, decisions pertinent to T2 [7]. But each also brings distinct readings of the evidence to its decisions [8].

Experts on the diffusion of innovations suggest that adopters of an innovation can be reliably categorized into five groups:

- Innovators: Between two and three percent of adopters are true innovators. They tend to be adventurous, open to new ideas, decisive, willing to take risks, highly educated, and connected to cutting-edge sources of information.

- Early Adopters: Studies indicate that early adopters comprise about $14 \%$ of all adopters. They are typically popular among their peers, smart, and well educated. They are less creative and less venturesome than the innovators but still enjoy being at the forefront of new medical advances.

- Early Majority: About one-third of adopters are deliberate in assessing innovations. They take their time, prefer others to take the lead in advancing business or policy, and are more informally connected to thought leaders.

- Late Majority: Another one-third of adopters are skeptics and traditionalists. With fewer resources, less expertise owing to more moderate educational levels, they are risk adverse, rather indecisive, and cautious in adopting, implementing, and evaluating innovations.

- Laggards: About 16\% of adopters are laggards. They are highly risk adverse, isolated from instructive sources of information, peer groups, and instinctively conservative.

Applying the general theory of innovation diffusion above to the biopharmaceutical arena, we can depict a diffusion S-curve that represents biopharmaceutical innovation (Fig. 1).

Pending approval, certain drugs may be used experimentally during the period prior to launch $\left(t_{O}-t_{L}\right)$ [9]. From the point of product launch, initially, only a few early adopters utilize an innovation. When Everett Rogers first coined the S-curve, the early adopters of biopharmaceutical innovations were strictly physicians, hospitals, and patients. At present, payers are the major adopters of biopharmaceutical innovations, as, over the past 30 years, they have assumed a substantial portion of the cost of prescription drugs [10].

As more use and pay for a newly marketed drug, others see it in use, or hear about the drug through sales and marketing personnel, or see it mentioned in the media as well as peer-reviewed and trade journals [11]. If early adopters perceive the innovation as providing better value than existing alternatives, others begin to use it as well. Once diffusion reaches a critical mass (point of inflection $C$ ), the number of adopters increases rapidly. At a certain point, the innovation reaches the part of the population that is least likely to adopt it and the diffusion rate slows to its saturation point (point $\mathrm{S}$ ). After the saturation point, cumulative market penetration declines, due, for instance, to generic competition, or competition from other branded drugs within a product's therapeutic class.

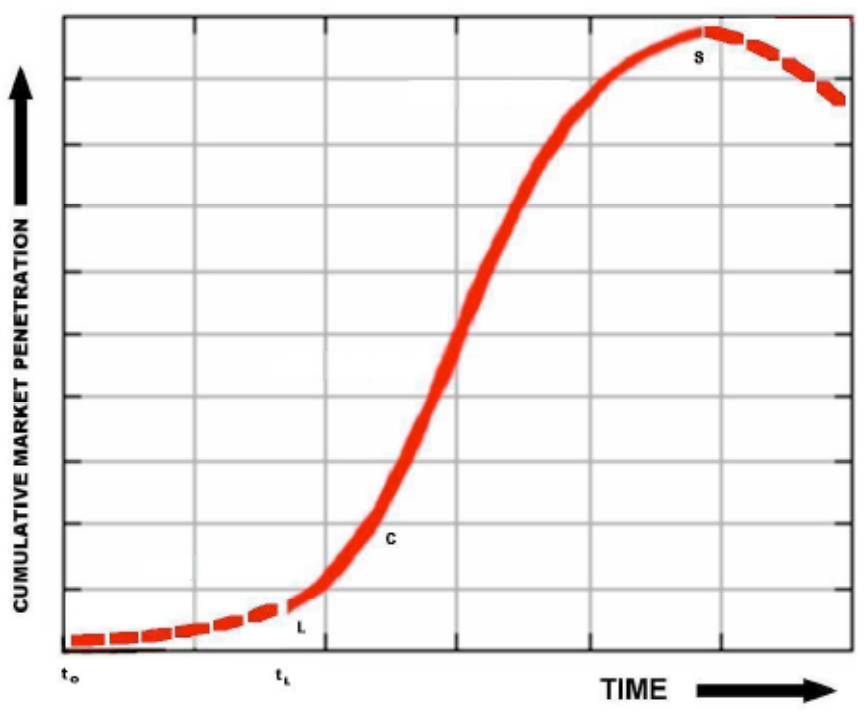

\section{INNOVATION ADOPTION RATE}

Fig. (1). Diffusion S-curve. The dashed line between $t_{O}$ (development of initial biopharmaceutical compound) and $t_{L}$ (point of launch) is the period during which a drug may be used experimentally. At point $\mathrm{C}$ the drug has reached a critical mass from which it diffuses rapidly. At point $\mathrm{S}$ the drug has reached its saturation point, after which sales, and therefore market penetration, fall off owing to generic competition or competition within its therapeutic class.

To illustrate, the monoclonal antibody Herceptin ${ }^{\circledR}$ was originally approved for advanced stage breast cancer, where the disease has spread within the breast or to another organ. Herceptin ${ }^{\circledR}$ was prescribed to desperately ill patients as an investigational new drug (IND) treatment prior to approval in Phase III studies [12]. Subsequently, post-approval studies suggested it could benefit patients in the early stages of the disease. These studies increased its off-label use, thus generating more drug diffusion. In November 2006, the Food and Drug Administration (FDA) approved the new indication for early-stage breast cancer, further boosting sales of the drug. Herceptin $^{\circledR}$ now has competitors, including Avastin, ${ }^{\circledR}$ which may halt its rapid diffusion.

There are numerous factors involved in determining positioning on the S-curve, the most important of which is knowledge transfer. Knowledge transfer generally flows from developers to physicians, patients, and payers, through sales and marketing, clinical education programs, patient advocacy, as well as public policy initiatives. In the case of Herceptin $^{\circledR}$, for instance, public health campaigns raised breast cancer awareness, thereby informing the public about diagnostic and therapeutic options [13].

Little research has been done to analyze what is commonly referred to as the second translational block: What happens to a drug from the time it is approved to when it is used in everyday clinical practice? How do physicians, pa- 
tients, and payers arrive at prescribing and coverage decisions? In this study, we attempt to fill this void.

In this study, we will first map the stakeholders involved in the translational process of innovation diffusion, and explain the evolving role of each stakeholder over time. The five instrumental stakeholders are:

$\bigcirc$

Biopharmaceutical industry that researches, develops, communicates the benefits, risks, and costs of, and sells new biopharmaceuticals;

- Regulatory agencies that evaluate the safety, efficacy, and quality of manufacturing practices surrounding each new drug;

- Physicians who decide whether to prescribe each new drug and obtain the requisite training and education to use each new drug appropriately;

- Patients who must give consent to the use of new technologies;

Payers who decide on reimbursement of each new drug.

Second, we describe the dynamic nature of the translational process while identifying T2 barriers. Third, using a survey instrument designed specifically for this study, for a sample of 20 high impact biopharmaceutical innovations, we empirically assess the relative innovativeness and rate of diffusion of these drugs. The empirical component in our study captures the early to late adopters along the S-curve, along with insight into the reasons for early and late adoption. The three key findings from our survey are a) there is a delay between approval and market adoption, even for highly innovative biopharmaceuticals; b) the more innovativeness (i.e., value) physicians and payers perceive an innovation has, the greater market share it gains; and c) there is a gap between physicians and payers in terms of the degree to which they value biopharmaceutical innovations, with physicians ranking drugs as more innovative than payers. Fourth, we will discuss our findings' policy implications regarding how payers could strike an appropriate balance with respect to biopharmaceutical diffusion.

\section{SECOND TRANSLATIONAL BLOCK}

The drug development, adoption, and diffusion processes are lengthy, complex, costly, and labor-intensive. The translation of information gained in the earliest stages of research into knowledge that will impact actual clinical practice involves four distinct functions:

- Basic biomedical research conducted domestically at the National Institutes of Health (NIH), or abroad at $\mathrm{NIH}$ counterparts, as well as domestic and foreign academic health centers;

○ Applied drug development carried out by the global research-based biopharmaceutical industry;
Sales and marketing professionals representing the global research-based biopharmaceutical industry interacting with physicians and payers, both pre- and post-approval;

- Evaluation of the relative innovativeness (i.e., value) of newly approved drugs by physicians, payers, policymakers, and patients.

The first translational block involves the transfer of new understanding of disease mechanisms gained in the laboratory, refined in animal testing, and applied in clinical studies among humans: functions 1 and 2 above. Federally sponsored basic research in genomics, molecular biology, and other life sciences has greatly expanded the drug industry's technological opportunities, stimulating private investment in applied biopharmaceutical R\&D [14].

The second translational block - functions 3 and 4 - involves the transfer and adoption of knowledge gathered during drug development into everyday clinical practice, covering the period between a drug's approval and its actual use.

\subsection{Dynamic Model of Innovation}

The traditional, but now caricatured, perception of medical innovation, which we will call exogenous innovation, is one in which scientists dream up a novel idea. The concept then moves in a linear progression, from the laboratory to animal models, to select populations, and finally to the bedside (see Fig. (2) below) [15]. The sequence of activities is driven first by "technology push" or basic advances in medical knowledge and applications. Secondly, innovation is stimulated by "market pull" or demand for solutions to existing maladies. Such demand leads to economic opportunities that provide incentives for risk-taking investment by the research-based medical industry, including biopharmaceutical firms [16]. In sum, the development of new biopharmaceuticals is influenced on the supply side by advances in scientific and engineering knowledge, and also demand for new biopharmaceuticals.

This linear conceptualization only captures part of reality. It makes a neat and clear-cut distinction between R\&D leading to innovation, on the one hand, and adoption and diffusion on the other, with most if not all of the inherent uncertainty in innovation attached to the former.

A more realistic scenario is endogenous innovation, which is depicted in Fig. (3) below. Endogenous innovation is generated cyclically within a system of stakeholder relations. While the biopharmaceutical industry is the largest funder of applied clinical research in the US, it builds upon publicly funded basic research (e.g. NIH). Accordingly, the biopharmaceutical industry does not start out with a blank chalkboard [17]. At the same time, the NIH agenda is partly a function of what is happening downstream with patients, physicians, and the biopharmaceutical industry. Basic research is not performed in a vacuum. That is, NIH takes its



Fig. (2). Linear Chain of Innovation. Adapted from: Gelijns et al. 1991. See ref. [18]. 


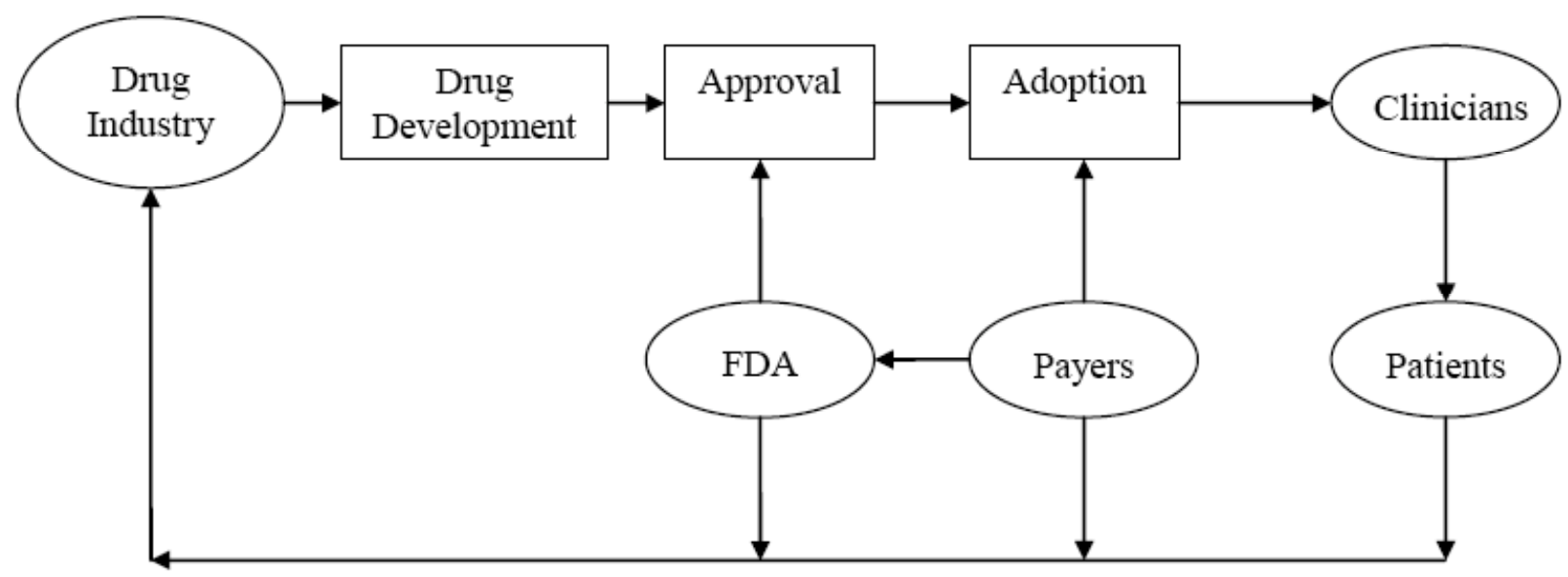

Fig. (3). Dynamic Chain of Innovation.

cue for conducting specific kinds of basic research from the diseases prevalent at any given point in time, and also physician, public health, and payer concerns. Indeed, observers note that NIH must "sustain a productive dialogue on enhancing clinical research with its partners: the academic health centers, private foundations, and the biopharmaceutical and managed health care industries".

Furthermore, it is a misconception to posit that all uncertainty has been ironed out by the time a new technology is introduced into clinical practice [18]. There have been numerous examples of drugs that turned out to have negative safety and cost-effectiveness post-approval. While the media tends to focus on examples of negative feedback brought about by post-marketing surveillance that result in market withdrawals of unsafe products, such as Baycol ${ }^{\circledR}$ and Vioxx, ${ }^{\circledR}$ there are many more instances that go unnoticed in which post-approval feedback on safety as well as clinicaland cost-effectiveness is positive [19, 20].

At the time a drug is launched there is often only limited knowledge of its clinical- and cost-effectiveness. Additionally, clinical- and cost-effectiveness estimates prior to launch - data collected during Phase III - are subject to an especially high degree of uncertainty that can only be resolved once the drug has extensively diffused into everyday clinical practice. Had preliminary cost-effectiveness analyses been allowed to determine whether erythropoietin, beta interferon, donezepil, and numerous other drugs targeting life-threatening diseases should reach the market, major medical advances would have been denied to large numbers of patients [21].

As drugs diffuse, payers serve as important repositories for post-approval medical data, including hospital, physician, and pharmacy claims. Additionally, implementation of the Medicare prescription drug benefit (Part D) is providing the Centers for Medicare and Medicaid Services (CMS) with pharmacy claims data pertaining to over 40 million Medicare beneficiaries [22]. CMS could potentially link up this data with the inpatient, physician, and outpatient data already on record [23]. As a result, much more could be learned about the (cost)-effectiveness of pharmaceutical care.

Over time, certain medications have proven to be cost saving (e.g., anti-ulcer drugs) [24], or cost-effective in comparison with existing non-biopharmaceutical therapy (e.g., erectile dysfunction drugs) [25], or cost-effective when tar- geting a specific sub-group (e.g., statins for patients at high risk of developing coronary artery disease) [26]. Other drugs have not proven to be cost-effective relative to conventional cost-effectiveness norms (e.g., beta-interferon), yet have demonstrated sufficient effectiveness to pass muster with most reimbursement authorities, particularly in light of the lack of existing treatment alternatives and the severity of the disease being targeted [27].

Also, when drugs are introduced into clinical practice, new indications, in one or more therapeutic classes, may be found [28]. Propecia ${ }^{\circledR}$ is the brand name for finasteride, an oral hair loss medication. Originally marketed under the brand name Proscar, ${ }^{\circledR}$ finasteride was first developed and prescribed as a treatment for enlarged prostates. Over time, many of the drug's users and their physicians noticed new hair growth and diminished thinning of the hair. This led to development of Propecia ${ }^{\circledR}$ - a lower dosage finasteride pill indicated for hair loss.

Another compelling example is rituxamab, indicated for certain types of non-Hodgkin's lymphoma, and now indicated for entirely different conditions, including rheumatoid arthritis. This followed large-scale R\&D on the part of rituxamab's sponsor.

\subsection{Degrees of Innovativeness}

Drug innovation is manifold and falls on a continuum in terms of innovativeness. At one end of the spectrum, it focuses on developing drugs about which relatively little is known at the time of their discovery, with an entirely new molecular structure or mechanism of action, or possibly targeting diseases for which there are no therapeutic alternatives. At the other end, innovation consists of developing drugs with mechanisms of action and molecular structures that have already been established, targeting diseases for which there exist therapeutic alternatives. The former may be classified as "radical breakthroughs" and the latter "incremental innovations."[29] While most first-in-class drugs are radical breakthroughs, follow-on drugs are not necessarily considered incremental innovations. Some may be breakthroughs. And, the accumulative effect of multiple followons may turn out to entail a radical breakthrough in biopharmaceutical care. As such, the first-in-class, follow-on distinction does not provide unambiguous guidance on a drug's degree of innovativeness [30]. 
Experts suggest that technological change proceeds akin to evolution [31], largely because advances are not the result of conscious planning and design. In fact, much of what counts as breakthrough may be fortuitous, as firms often independently and simultaneously engage in a competitive race to develop new drugs with the same mechanism of action in the same therapeutic class [32-34].

By offering a scientific basis, the FDA appears to give more guidance in classifying degrees of innovativeness. First, the FDA classifies all new drug applications (NDAs) on two dimensions: by chemical type and therapeutic potential. One measure of innovation is the newness of the compound forming the drug's active ingredient. FDA designates drugs that are compounds that have never before been approved as new molecular entities (NMEs). Second, the FDA denotes clinical improvement as another feature of innovation. The FDA uses the degree of expected clinical improvement as a basis for assigning NDAs to either the standard or priority review track. Specifically, drugs qualify for priority review when there is evidence of the potential for significant clinical improvement relative to existing treatment options, or reduced side effects and drug-drug interactions. Third, the FDA assigns special status to certain drugs, through accelerated approval and fast-track mechanisms [35]. The latter refers to a formal mechanism to expedite the approval process for drugs that address an unmet medical need. The accelerated approval mechanism makes promising products for life-threatening diseases available on the market on the basis of preliminary evidence prior to a formal demonstration of patient benefit. Fourth, FDA designates orphan status to drugs treating orphan diseases or diseases with a low prevalence in the population. In the empirical section (4) of this study, we sample 10 priority and 10 standard NMEs, of which four have fast track designations, five have accelerated approval, and two have orphan status.

\subsection{Technology Assessment}

The FDA is charged with licensing new drugs, based on the traditional hurdles of safety, efficacy, and quality of manufacturing practices. The standard of effectiveness employed by the FDA consists of new therapeutic agents being assessed in randomized clinical trials against a placebo. Once a drug is approved, it can be sold to any entity willing to pay the market price. Traditionally, physicians, acting as agents on behalf of their patients, were considered the principal decision makers by the developers of new drugs [36]. The main communication channel to promote drug diffusion was through the drug industry's detailing and advertising, which for decades almost exclusively targeted physicians. But, rather than simply deferring to physicians in their decisions regarding which drugs to choose, patients now are increasingly viewed as shared decision makers. Consequently, the industry has boosted its advertising pitched directly to patients, particularly since implementation of the FDA Modernization Act of 1997, which relaxed rules on direct to consumer advertising.

An even more important trend that has been evolving over the past two decades is the wielding of considerable influence by payers on the demand for drugs. Payers are erecting a fourth hurdle to market access, heralding a transition from a health care system in which hundreds of thou- sands of clinicians and hundreds of millions of patients are the major adopters toward one in which buying and therefore decision making power is concentrated in a much smaller number of private and public insurers. Here, we define fourth hurdle as the requirement that the biopharmaceutical industry submit pharmacoeconomic data to payers who, in turn, based on the furnished information, determine pricing and reimbursement [37]. The fourth hurdle is often explicit and mandatory overseas, while it is implicit and voluntary in the US.

In theory, reimbursement decisions are a function of a drug's price and quality. Here, price is the result of negotiations between the drug industry and purchasers, while quality is measured in terms of a drug's life-extending and quality-of-life enhancing benefits. Ultimately, however, how payers decide the price/quality trade-off is fraught with countervailing interests and considerations, some strictly clinical or economic, others political and even ethical. In order to streamline and depoliticize this process as much as possible, an increasing number of payers turn to technology assessment, which they outsource or perform in-house. Technology assessment refers to any rigorous process of examining and reporting properties of a medical technology used in health care, such as safety, clinical effectiveness, indications for use, and sometimes cost. It is usually comparative in nature, hence the term comparative effectiveness, which implies comparing a new technology's safety, efficacy, and cost to an existing treatment alternative. Costeffectiveness analysis is a unique subset of comparative effectiveness analyses as it compares the incremental cost of one intervention to another with the incremental gain.

Technology assessment began as an offshoot of the evidence based prescribing and clinical practice guideline movements, originally concentrating on expensive new technologies, including so-called specialty biopharmaceuticals and highly specialized surgical interventions. Proliferation of high profile big-ticket items with uncertain health outcomes raised questions about their appropriate use. Furthermore, inexplicable geographic variations in clinical practices pointed to a problem that needed addressing.

Over the past 30 years, technology assessment in the US has been dispersed among both public and private entities. In stark contrast to most other countries, in the US, private sector initiatives originally dominated technology assessment. The most prominent ongoing initiative is Blue Cross Blue Shield's (BCBS) Association's Technology Evaluation Center (TEC), founded in 1985 [38]. TEC employs a set of five criteria to evaluate whether to (conditionally) reimburse health interventions, including drugs:

- Technology must be approved by the FDA;

- Scientific evidence must support judgments about the intervention's effect on health outcomes;

- Intervention's beneficial effects should outweigh any harmful effects, and thus improve net health outcomes;

- Intervention must be as beneficial as any established alternative;

- Intervention's benefits must be achievable under the usual conditions of medical practice. 
Cost is notably absent from TEC's list of criteria. However, by 1998, Regence Blue Shield in Washington State became the first US health insurance organization to require economic evidence as a condition of formulary review. Since that time, several major insurers have followed suit, including many other BCBS subsidiaries, as well as WellPoint, Kaiser Permanente, and the Oregon Medicaid agency. The Regence initiative became a template for formulary guidelines drafted by the Academy of Managed Care Pharmacy (AMCP) in 2001. These guidelines contain recommendations regarding what evidence drug manufacturers should submit to third party payers for their products' formulary placement. AMCP standards not only serve to signal the kind of information that payers consider necessary for making formulary decisions, they are also supposed to reduce the uncertainties and costs that manufacturers face in preparing documentation for coverage reviews by multiple health plans.

Public sector initiatives began in earnest in 1999 when Congress reauthorized the Agency for Healthcare Research and Quality (AHRQ), expanding the agency's charge to include evaluation of the cost and use of medical devices, promotion of evidence-based practices, and comparison of effectiveness of biopharmaceuticals. Once again, cost is conspicuously absent from AHRQ's mandate regarding pharmaceuticals.

AHRQ's activities to promote evidence-based health care practices are organized around its support of 13 EvidenceBased Practice Centers (EPCs). These 13 Centers include academic, as well as clinic- and practice-based research groups that have access to electronic health information databases, with which to address questions of health outcomes and comparative clinical effectiveness. During the past eight years, AHRQ's initiatives have focused on ten priority conditions, selected because of their high impact on Medicare, Medicaid, the State Children's Health Insurance Program (SCHIP), and other federal health programs:

$\begin{array}{ll}\circ & \text { Arthritis and non-traumatic joint disorders; } \\ \circ & \text { Cancer; } \\ \circ & \text { Chronic obstructive pulmonary disease and asthma; } \\ \circ & \text { Dementia including Alzheimer's disease; } \\ \circ & \text { Depression and other mood disorders; } \\ \circ & \text { Diabetes mellitus; } \\ \circ & \text { Ischemic heart disease; } \\ \circ & \text { Peptic ulcer disease and dyspepsia; } \\ \circ & \text { Pneumonia; } \\ \circ & \text { Stroke and hypertension. }\end{array}$

More recent public sector initiatives include the Drug Effectiveness Review Project (DERP); an alliance of 15 state and two private organizations, founded in 2003, which have pooled resources to synthesize and judge clinical evidence for drug class reviews. In selecting which classes to review, DERP participants give priority to drug classes that account for a large share of pharmacy budgets, classes consisting of many competitors, those with substantial off-label use, and those with recent additions of costly drugs. Each evidence review is conducted by one of three AHRQ-designated
EPCs. Per a decision by DERP participants, the EPCs consider clinical evidence only and do not take evidence on cost-effectiveness into account.

From a public policy vantage point, the Medicare Prescription Drug, Improvement, and Modernization Act of 2003 (MMA) constitutes a watershed for the systematic use of technology assessment. The MMA is expected to give clinical- and cost-effectiveness data a more prominent role in drug coverage decisions, but at the level of the private plan, rather than at the national level [39]. Nevertheless, as a result of MMA the technology assessment landscape is in flux and acquiring a more national character. For example, the MMA has directed AHRQ to conduct or support an expanding comparative effectiveness research agenda. Thus far, AHRQ has evaluated the comparative effectiveness of health interventions aimed at diseases, including asthma, cancer, dementia, diabetes mellitus, peptic ulcer, and stroke. Future research will include evaluation of formulary management by Medicare payers and linkage of CMS disease registries with prescription drug claims databases.

AHRQ's outcomes research shows that technology assessment does not invariably constitute a barrier to industry innovation and diffusion. It may also represent an opportunity, especially for firms that can demonstrate their drugs' comparative clinical- and cost-effectiveness relative to competitors. In fact, spokespersons from several large drug companies have been quoted as saying that they do not believe imposing cost-effectiveness data requirements is necessarily threatening because companies are already providing such information in the European, Canadian, and Australian markets.

Like AHRQ, but much more systematically and extensively, the British NICE analyzes the comparative clinicaland cost-effectiveness of selected newly licensed drugs. NICE offers the British National Health Service (NHS) recommendations on whether to prescribe, to whom, and with what conditions of reimbursement. On average, it takes about one year from a product's launch date for NICE to complete each technology assessment [40]. British law currently stipulates that the NHS fund drugs that have received positive recommendations, while negative recommendations do not automatically lead to coverage denials. Pundits ask whether AHRQ will evolve into a NICE-like entity. It is unlikely that AHRQ would morph into a NICE-like body, given that the US does not have a single payer system. Nor does the AHRQ mandate include cost considerations in its appraisals. And US law expressly forbids AHRQ's findings from becoming binding policy recommendations. Nevertheless, political support is growing for a federal comparative effectiveness agency. Such an agency would examine the relative medical benefits and risks of treatment options and possibly even weigh the benefits against the costs. The results could be used as a guide for insurers to modify their coverage or payment policies, altering the incentives facing physicians and patients [41].

\section{MAPPING STAKEHOLDERS INVOLVED IN THE TRANSLATIONAL PROCESS OF INNOVATION DIFFUSION}

As was said above, the value of each biopharmaceutical innovation is subject to differing interpretations by each 
stakeholder, while diffusion turns on knowledge transfer regarding a drug's perceived innovativeness. Before we review the role of payers and physicians, whom we view as most crucial to the innovation diffusion process, let us briefly consider the roles of the other three key stakeholders.

First, the biopharmaceutical industry: This industry plays an indispensable role in respect to developing innovations and diffusing them across the population. Besides doing the applied research, manufacturing, and distribution of pharmaceuticals, the industry promotes adoption and diffusion by channeling information to physicians via detailing, to patients per direct to consumer advertising, and to payers through formulary submission dossiers.

The FDA's stamp of approval is a necessary but insufficient condition for a drug's success in the marketplace. Regardless of a drug's merits as shown in clinical trials, the message needs to be transmitted to physicians, payers, and patients who make the adoption decisions. Before prescribing a new drug, for example, doctors must become acquainted with the drug's therapeutic advantages vis-à-vis alternatives, its correct dosage, and its properties stratified across different patient sub-populations. One way to convey the message is to spread the word at academic as well as trade conferences, and in peer-reviewed journals. Yet, the communication of new ideas and products through academic media can be both cumbersome and time-consuming. Firms may even sponsor clinical trials whose primary purpose is to familiarize participating doctors with the firm's new products. A recent Congressional Budget Office study concluded that doctors who conduct clinical trials sponsored by a drug firm subsequently increased their prescribing of the drug sponsor's products [42]. Though controversial in some instances, it makes economic and clinical sense for the drug industry to become involved in continuing medical education, physician detailing, and disease management.

Currently, the biopharmaceutical industry is confronted with enormous pressure from payers to demonstrate each new drug's therapeutic value with scientific rigor. Generally, the more innovative a drug is perceived, the higher its relative price, that is, payers will be willing to pay more for something that does more. Besides therapeutic value, other decision criteria that drive payer formulary decisions include safety, compliance, cost-effectiveness, and equity considerations.

Second, the FDA functions as chief intermediary and facilitator in the drug development process. Through a series of legislative initiatives, the FDA has stimulated development of biopharmaceutical innovations. Examples include orphan drug, accelerated approval, and fast-track legislation. The FDA also plays an important role in sanctioning labeling and package inserts, as well as providing warning messages to patients and physicians (e.g., black box warnings).

Third, in an era in which patients know and demand more, an increased amount of stimulus for the development of new innovations is coming directly from the patient constituency. In effect, patients, (but also legislators and the media) represented by patient advocacy groups are shaping the political costs to the FDA of delaying drug approval. Likewise, they shape the political costs to the insurance industry of delaying reimbursement appraisals and denying coverage $[43,44]$.

The biopharmaceutical industry regularly seeks alliances with patient advocates in pressing the case for expediting the development of drugs deemed especially important to public health. Prior to the 1980s it was rare for the public's attention to be drawn to a drug that the FDA had not approved or was reviewing slowly. The AIDS epidemic appears to have altered the landscape dramatically. AIDS activists successfully lobbied for earmarking money for basic research in HIV/AIDS, restructuring clinical trials, effecting changes in the criteria for assessing the safety and effectiveness of new drugs treating AIDS, and securing classification of HIV/AIDS as a disabling condition under the Social Security Act. This ensured AIDS patients would be reimbursed as Medicare beneficiaries.

At present, to a degree not witnessed before, diseasespecific lobbies, particularly in the cancer arena, compel Congress to fund more biopharmaceutical research, request speedier approvals from the FDA for life-saving treatments, and pressure public and private insurers for more favorable coverage rulings.

Now we turn our attention to the two key stakeholders involved in the innovation diffusion process: physicians and payers.

\subsection{Physicians}

The final critical phase in the biopharmaceutical innovation process is the introduction of new drugs into general usage. Historically, clinicians have been the dominant decision makers, and the drug industry has looked primarily to them to achieve rapid diffusion. What determines physician uptake is still somewhat of a black box. We do know that clinical decisions have traditionally been based on data published in peer-reviewed publications and academic/trade conference proceedings, but also information provided through the drug industry's sales and marketing representatives.

As the role of insurance has grown over time, clinicians have been made more acutely aware of health care costs. Clinicians select therapies to treat patients within a technologically feasible set of treatment alternatives, but are also subject to resource constraints. These constraints depend largely on the type of insurance system in place. It is usually someone else's money that pays for medical services; hence the phrase third party payer.

The two types of insurance payment mechanisms - retrospective, which pays a physician on the basis of costs incurred, and prospective, which pays sums that are independent of those costs incurred - imply profoundly different incentives for drug diffusion. Under a retrospective fee-forservice system, there is little incentive to weigh costs against effectiveness. So long as a new drug has positive expected value it is financially feasible to prescribe. As a result, there is a demonstrable "proclivity of doctors and hospitals to adopt almost any plausible new thing - drugs, surgical methods, equipment - that increases capability in any dimension ... without regard for cost.'[45] By contrast, under a capitated, prospective payment system physicians are forced to consider cost consequences of their prescribing decisions. 


\subsection{Payers}

Perhaps contrary to conventional wisdom, given recent extensive media coverage of the increased cost share burden on consumers, the percentage of consumer out-of-pocket spending on prescription drugs has been dropping steadily over the past several decades: from close to $70 \%$ in 1980 , to $50 \%$ in 1990 , and less than $30 \%$ in 2005 [46]. As payers cover more drug costs, their scrutiny of what they cover is increasing. Accordingly, payers have adopted a more assertive role in decision making through formulary management and direct involvement of clinicians in budget holding and sharing of financial risk.

Comparisons of the clinical- and cost-effectiveness of newly approved drugs are gaining traction among formulary managers. While the FDA examines placebo-benchmarked trial data, payers are more interested in head-to-head data to inform formulary decisions. Formulary managers are usually confronted with a new intervention that is better than current standard practice, but which costs more. They must then decide what increase in health is likely to accrue from the increase in expenditure, and whether such an increase is worth it.

Fewer than $50 \%$ of US payers admit to currently using formal cost-effectiveness analyses [47]. Nevertheless, several dozen BCBS subsidiaries have recently adopted the use of cost-effectiveness analyses to evaluate newly approved drugs. In addition, the nation's second largest insurer WellPoint has declared it will mandate use of technology assessment guidelines, beginning in 2009. Insurers are looking abroad for help in incorporating economic evaluations of newly approved drugs.

From the limited data available, it appears most drugs with favorable formulary placement have "reasonable" costutility ratios, below a conventional cost-effectiveness threshold [48]. However, there are examples of cost-effective drugs that are either not reimbursed or placed in high cost share tiers, and examples of drugs with unfavorable costeffectiveness profiles that are included on formularies. This suggests that formulary decisions are complex and reflect multiple factors, including the ability to negotiate favorable rebate mechanisms and cost-effectiveness, but also the extent to which drugs have treatment alternatives and the severity of the disease targeted by the drug [49].

Reimbursement decision-making is a balancing act. There are different kinds of cost that must be accounted for: direct acquisition cost of drugs, hospital in-and outpatient, and physician visit cost. Similarly, there are different measures of effectiveness: increased longevity, improved quality of life, fewer side effects, and better patient compliance. In addition, intangibles play a role in determining formulary listing. They impact both the cost and effectiveness side of the ledger. First, ethical and legal constraints may force formulary managers to add a new drug to the formulary regardless of its cost-effectiveness. For example, an orphan drug may have a poor cost-effectiveness ratio, yet be included on the formulary on account of its orphan status. Second, patient and physician satisfaction with a drug's dosing or formulation may influence the decision to reimburse. Third, a drug's effect on worker productivity, by reducing the number of sick days, for instance, may be taken into account. Table 1 lists the items included under the cost, effectiveness, and intangible rubrics.

Table 1. Payer Considerations

\begin{tabular}{|c|c|c|}
\hline Effectiveness & Cost & Intangibles \\
\hline \hline $\begin{array}{c}\text { Increased life } \\
\text { expectancy }\end{array}$ & $\begin{array}{c}\text { Direct acquisition } \\
\text { cost of biopharma- } \\
\text { ceuticals }\end{array}$ & $\begin{array}{c}\text { Ethical and legal } \\
\text { constraints }\end{array}$ \\
\hline Improved quality of life & Cost of hospital care & $\begin{array}{c}\text { Patient and physi- } \\
\text { cian satisfaction }\end{array}$ \\
\hline $\begin{array}{c}\text { Improved side effect } \\
\text { profile and compliance }\end{array}$ & $\begin{array}{c}\text { Cost of physician } \\
\text { care }\end{array}$ & $\begin{array}{c}\text { Productivity gains } \\
\text { and losses }\end{array}$ \\
\hline
\end{tabular}

\section{CASE STUDY: INNOVATIVENESS AND DIFFU- SION FROM PHYSICIAN AND PAYER PERSPEC- TIVES}

The development of drugs and their diffusion do not take place in a vacuum but are influenced by the availability and development of competing medical interventions. Therefore, it is imperative we examine the relative value of biopharmaceutical innovations, compared to already existing standards of care. We could simply choose to analyze aggregated data to find out about diffusion, and infer relative value from the data. But, there are distinct advantages to asking stakeholders directly. The aggregated data do not provide us with a direct measure of relative innovativeness, nor insight as to why certain drugs are valued more than others by key stakeholders.

\subsection{Sampling, Data Collection}

We sampled 20 NMEs: 10 standard and 10 priority review drugs, 19 of which are outpatient medications (see Table 2 below). Our sampling includes the top 10 selling priority NMEs from the top 200, ranked by retail sales in 2005 , and the top 10 selling standard NMEs from the top 200 , ranked by retail sales in 2005 [50]. The 20 NMEs are indicated for nine out of the ten priority conditions selected by AHRQ.

The FDA approved all drugs in our sample after 1999 (see Table 2 below). Our sampling of 20 top-selling NMEs not only represents drugs with a high cost impact, it also reflects varying degrees of innovativeness as judged by different FDA designations.

It is important to note that both priority and standardrated NMEs can be considered innovative. Priority-rated Gleevec $^{\circledR}(2001)$ is clearly highly innovative. It is the first drug approved to treat cancer by interfering with the action of an abnormal protein that is produced in chronic myeloid leukemia. Likewise, priority-rated Tarceva ${ }^{\circledR}(11 / 18 / 2004)$ is widely considered highly innovative. It is the first-line therapy indicated for the treatment of patients with locally advanced or metastatic non-small cell lung cancer after failure of at least one previous regimen of chemotherapy. At the same time, standard-rated Humira ${ }^{\circledR}(12 / 31 / 2002)$ is viewed among clinicians as highly innovative, as the firstline therapy approved for the treatment of rheumatoid arthritis, psoriatic arthritis, and ankylosing spondylitis. In addition, standard-rated Forteo ${ }^{\circledR}(11 / 26 / 2002)$ is considered by 
many to be highly innovative, as the first-line therapy approved for treatment of osteoporosis.

Table 2. Sample of 20 NMEs

\begin{tabular}{|c|c|c|}
\hline $\begin{array}{c}\text { Drug Name (Generic) } \\
\text { Standard vs Priority } \\
\text { Status - Mark with } \\
\text { an S or a } P\end{array}$ & $\begin{array}{l}\text { Drug Name (Brand) } \\
\text { Different Column } \\
\text { for Rating }\end{array}$ & Indication \\
\hline Aripiprazole S & Abilify $^{\circledR}$ & $\begin{array}{l}\text { Bipolar Disorder } \\
\text { and Schizophrenia }\end{array}$ \\
\hline Rabeprazole S & Aciphex $^{\circledR}$ & GERD \\
\hline Pioglitazone P & $\operatorname{Actos}^{\circledR}$ & Diabetes \\
\hline Rosiglitazone P & Avandia ${ }^{\circledR}$ & Diabetes \\
\hline Rosuvastatin S & Crestor $^{\circledR}$ & Cholesterol \\
\hline Duloxetine S & Cymbalta $^{\circledR}$ & Anti-depressant \\
\hline Enfuvirtide P & Fuzeon $^{\circledR}$ & HIV \\
\hline Imatinib mesylate $\mathrm{P}$ & Gleevec $^{\circledR}$ & Anti-neoplastic \\
\hline $\begin{array}{c}\text { Lopinavir \& } \\
\text { ritonavir P }\end{array}$ & Kaletra $^{\circledR}$ & HIV \\
\hline Insulin glargine $\mathrm{S}$ & Lantus $^{\circledR}$ & Diabetes \\
\hline Bimatoprost $\mathrm{P}$ & Lumigan $^{\circledR}$ & Cardiovascular \\
\hline Meloxicam S & Mobic $^{\circledR}$ & Arthritis \\
\hline Pantaprazole sodium $\mathrm{S}$ & Protonix ${ }^{\circledR}$ & GERD \\
\hline Atazanavir P & Reyataz $^{\circledR}$ & HIV \\
\hline $\begin{array}{c}\text { Atomexetine } \\
\text { hydrochloride S }\end{array}$ & Strattera ${ }^{\circledR}$ & ADHD \\
\hline Temozolomide P & Temodar $^{\mathbb{B}}$ & Anti-neoplastic \\
\hline Oxcarbazepine S & Trileptal $^{\circledR}$ & Epilepsy \\
\hline $\begin{array}{l}\text { Tenofovir disoproxil } \\
\text { fumarate } \mathrm{P}\end{array}$ & Viread $^{\circledR}$ & HIV \\
\hline Tegaserod maleate $\mathrm{P}$ & Zelnorm $^{\circledR}$ & IBS \\
\hline Ezetimibe $\mathrm{S}$ & Zetia $^{\circledR}$ & Cholesterol \\
\hline
\end{tabular}

Prior to conducting our physician survey, we examined the status of all 20 NMEs on the formularies of 22 leading payers participating in the Medicare prescription drug benefit. Cumulatively, these Medicare prescription drug plans (PDPs) enroll approximately 19 million Medicare beneficiaries, or half the total number of Medicare enrollees. We examined the formularies of Medicare prescription drug plans for two reasons: First, we considered the convenience of having a consistent and validated data source, namely, CMS. Second, Medicare is a driving force behind both public and private payer policy. Private health plans tend to follow Medicare in their coverage policies.

For 2007 filings, we examined formulary placement, cost sharing arrangements, and conditions of reimbursement. For each PDP, we examined the four-tier formulary with the highest Medicare beneficiary enrollment: tier one is primarily reserved for generics, tier two for preferred brands, tier three for non-preferred brands, and a fourth specialty tier, used mainly for biotechnology or injectable drugs [51]. We collected three types of data for each drug from the Formu- lary Finder: whether a drug was on plan formularies; the cost sharing tier for each covered drug; and whether prior authorization, quantity limits, or step therapy were applied as conditions of reimbursement. To estimate beneficiary cost sharing for each drug, we collected information on plan benefit designs, including cost sharing imposed by each sponsor's plan. We used the Medicare Prescription Drug Plan Finder on the Medicare website to identify each plan's negotiated price for purchases at retail pharmacies. When drugs were assigned co-payment tiers, we applied the plan's co-payment unless the plan's negotiated price was lower. When drugs were subject to co-insurance, we applied the coinsurance rate to the plan's negotiated price to estimate the amount a beneficiary would pay. In general, we used the Plan Finder's preset values for the most common form and strength of each drug.

Our physician survey elicited responses from physicians to measure relative valuation and diffusion (rates) of the 20 NMEs [52, 53]. In the spring of 2007, we sampled physicians from two sources: Greatlists and ePOCRATES. Physicians were identified using Greatlists (an independent supplier of American Medical Association marketing lists) and ePOCRATES, inc. (a company that sells mobile and webbased products that support clinical decision making). An invitation with the link to the survey was sent via email to 3,400 physicians (2,500 randomly selected American Medical Association general practice/internal medicine physicians from Greatlists and 900 physicians from ePOCRATES). One hundred ninety physicians responded, which implies a raw response rate of $5.5 \%$.

Physicians were first asked to provide information about their age and sex, the number of physicians in their practice, and the percentage of time devoted to patients. Subsequently, we asked physicians to assess the importance of various factors influencing their general prescribing decisions. These factors included professional journal publications, continuing medical education, payers' decisions, and pharmaceutical sales representatives. Next, we asked physicians to rank the importance of ten information sources for prescribing decisions. Each respondent was then asked to consider the innovativeness of each NME relative to an existing treatment alternative. Finally, we asked physicians to provide us with information on each drug's rate of diffusion as well as market share. Specifically, physicians were asked to report the date corresponding to the first time a drug was prescribed, in addition to the percentage of prescriptions written for each drug, for the disease the drug targets.

\subsection{Results}

Our physician survey covered a broad cross section of the physician population. The average age of our sample of physicians (47) corresponds to the average age nationwide. Most respondents are in suburban and urban group practice. And about $75 \%$ of survey respondents are male.

Peers and continuing medical education still influence physicians' prescribing decisions more directly than payers, patients, and pharmaceutical firms. However, payers are influencing physicians' prescribing decisions regarding newly approved drugs, partly because they currently fund over $60 \%$ of evidence-based continuing medical education activities [54]. 
Table 3. Characteristics of Physician Respondents

\begin{tabular}{|l|l|}
\hline Age (Years) & \\
Median & 46 \\
Mean & 46.72 \\
Range & $29-76$ \\
\hline Sex $\quad$ Male & $76.7 \%$ \\
Female & $23.3 \%$ \\
\hline Year Received Medical Degree & \\
Median & 1988 \\
Mean & 1987 \\
Range & $1956-2006$ \\
\hline Medical Community & \\
Inner City & $10.6 \%$ \\
Urban & $36.7 \%$ \\
Suburban & $44.7 \%$ \\
Rural & $8.0 \%$ \\
\hline Practice Setting & \\
Group & $33.3 \%$ \\
Private & $26.3 \%$ \\
Academic Medical Center & $23.7 \%$ \\
Community Health Clinic & $3.2 \%$ \\
Unaffiliated Hospital & $2.7 \%$ \\
VA Hospital & $3.2 \%$ \\
Other & $7.5 \%$ \\
\hline Number of patients served & \\
(in total practice, per year) & 2000 \\
Median & 3782.8 \\
Mean & $5-29,000$ \\
Range & \\
\hline Percent of total practice time face-to-face with & \\
patients & $90 \%$ \\
Median & $81.5 \%$ \\
Mean & \\
Range & \\
\hline
\end{tabular}

Physicians rank traditional information sources highly for their prescribing information. These sources include peerreviewed journals, clinical reference guides, and conference proceedings. Less traditional information sources, such as magazines, medical societies, and trade journals hardly figure as number one ranked sources of information for prescribing decisions. Surprisingly, formularies did not rank highly as a source of information, though clearly formularies must have an impact on physicians' prescribing behaviour as they delineate preferred medications.

We measured physicians' perception of innovativeness using self-reported scores obtained from the survey. Physicians were asked to rank each drug on a scale of 1 to 4 , with 1 being "very innovative." Respondents also had the option to choose, "I am not familiar with this drug." Table 4 shows the relative innovativeness of all 20 NMEs, as reported by our physician respondents in response to the question how innovative each drug is compared to existing therapeutic alternatives. Each column lists the cumulative percentage of physician ranks for each drug.

We also developed an innovativeness scale for payers for each drug. Each payer-drug combination was assigned a score from 1 to 9 , with 1 being the most innovative. This score was based on whether the drug is covered or not, the cost-sharing percentage (as determined by formulary tier, copayment, and price of drug), and the presence of conditions (i.e., quantity limits, step therapy, and prior authorization). We acknowledge that this scale is merely a proxy for innovativeness. It only takes into account several factors that are not necessarily reflective of innovativeness. Sometimes a drug's preferred formulary status may be more a function of the ability of health plans to negotiate steep rebates in exchange for preferred formulary placement.

In order to standardize the tiering across each payer, we assigned drugs to the following four tiers using our calculated cost-sharing percentages:



Fig. (4). Factors Influencing Prescribing Decisions. 




Fig. (5). Information sources for prescribing decisions.

○ Tier 1: $<10 \%$ cost sharing;

○ Tier 2: Between $10 \%$ and $24 \%$ cost sharing;
Tier 3: Between $25 \%$ and $49 \%$ cost sharing;

Tier 4: Over $50 \%$ cost sharing.

Table 4. Physician Rating of Innovativeness*

\begin{tabular}{|c|c|c|c|c|c|}
\hline Trade Name & Very Innovative & Somewhat Innovative & Not Very Innovative & Not at All Innovative & Not Familiar with Drug \\
\hline Gleevec $^{\circledR}$ & $49.6 \%$ & $8.6 \%$ & $2.6 \%$ & $0.9 \%$ & $38.5 \%$ \\
\hline Lantus $^{\circledR}$ & $62.4 \%$ & $29.5 \%$ & $4.7 \%$ & $0 \%$ & $3.4 \%$ \\
\hline Zetia $^{\circledR}$ & $63.3 \%$ & $26.7 \%$ & $5.3 \%$ & $0.7 \%$ & $4.0 \%$ \\
\hline Fuzeon $^{\circledR}$ & $19.3 \%$ & $12.6 \%$ & $1.68 \%$ & $0 \%$ & $66.4 \%$ \\
\hline Temodar $^{\mathbb{R}}$ & $11.0 \%$ & $7.6 \%$ & $0.9 \%$ & $0 \%$ & $80.5 \%$ \\
\hline Zelnorm $^{\circledR}$ & $37.7 \%$ & $42.3 \%$ & $3.9 \%$ & $4.6 \%$ & $11.5 \%$ \\
\hline Strattera ${ }^{\circledR}$ & $30.7 \%$ & $44.5 \%$ & $8.8 \%$ & $0 \%$ & $16.1 \%$ \\
\hline $\operatorname{Actos}^{\circledR}$ & $33.6 \%$ & $48.0 \%$ & $11.2 \%$ & $2.0 \%$ & $5.3 \%$ \\
\hline Lumigan $^{\circledR}$ & $9.6 \%$ & $15.7 \%$ & $4.4 \%$ & $0 \%$ & $70.4 \%$ \\
\hline Abilify $^{\circledR}$ & $19.7 \%$ & $42.3 \%$ & $8.0 \%$ & $0 \%$ & $30.0 \%$ \\
\hline Avandia $^{\circledR}$ & $29.9 \%$ & $51.0 \%$ & $11.6 \%$ & $3.4 \%$ & $4.1 \%$ \\
\hline Cymbalta $^{\circledR}$ & $26.8 \%$ & $52.3 \%$ & $13.7 \%$ & $2.6 \%$ & $4.6 \%$ \\
\hline Reyataz $^{\circledR}$ & $8.5 \%$ & $20.3 \%$ & $4.2 \%$ & $0.9 \%$ & $66.1 \%$ \\
\hline Viread $^{\circledR}$ & $9.5 \%$ & $19.8 \%$ & $5.2 \%$ & $0.9 \%$ & $64.7 \%$ \\
\hline Kaletra ${ }^{\circledR}$ & $9.5 \%$ & $19.8 \%$ & $5.2 \%$ & $0.9 \%$ & $64.7 \%$ \\
\hline Trileptal $^{\circledR}$ & $9.6 \%$ & $45.5 \%$ & $12.9 \%$ & $1.5 \%$ & $30.3 \%$ \\
\hline Crestor $^{(\mathbb{B}}$ & $16.2 \%$ & $44.8 \%$ & $28.6 \%$ & $7.8 \%$ & $2.6 \%$ \\
\hline Protonix ${ }^{\circledR}$ & $13.8 \%$ & $38.8 \%$ & $33.8 \%$ & $11.3 \%$ & $2.5 \%$ \\
\hline Mobic $^{\circledR}$ & $7.8 \%$ & $43.7 \%$ & $33.1 \%$ & $9.2 \%$ & $6.3 \%$ \\
\hline Aciphex ${ }^{\circledR}$ & $7.4 \%$ & $23.9 \%$ & $40.5 \%$ & $19.7 \%$ & $8.6 \%$ \\
\hline
\end{tabular}

* This table is arranged in order of mean innovativeness scores, beginning with the most innovative. 
We then assigned scores as follows: A drug in Tier 1 with no conditions was assigned a score of one, a drug in Tier 1 with conditions was assigned a score of two, a drug in Tier 2 with no conditions was assigned a score of three, etc. A drug that was off formulary was assigned a score of nine. Because all 20 NMEs were on patent at the time we examined each drug's formulary status, with the exception of meloxicam, we can safely assume that formulary placement, tiering, and conditions of reimbursement are not a reflection of a drug's patent status or generic availability, though coverage may still reflect the negotiating power of the health plan vis-à-vis the drug sponsor. Note, tegaserod maleate $\left(\right.$ Zelnorm $^{\circledR}$ ) was withdrawn from the market in 2007, and meloxicam $\left(\mathrm{Mobic}^{\mathbb{B}}\right)$ is now available as a generic. Of these two drugs we only removed meloxicam from our analysis.

Table 5 shows the frequency distribution of each drugpayer combination (19 drugs, 22 payers).

Table 5. Frequency Distribution of Payer Ranking

\begin{tabular}{|c|c|c|c|c|c|}
\hline & Tier 1 & Tier 2 & Tier 3 & Tier 4 & Not Covered \\
\hline No Conditions & $\begin{array}{c}31.10 \% \\
(1 *)\end{array}$ & $\begin{array}{c}5.26 \% \\
(3)\end{array}$ & $\begin{array}{c}21.29 \% \\
(5)\end{array}$ & $\begin{array}{c}0.48 \% \\
(7)\end{array}$ & \multirow{2}{*}{$\begin{array}{c}7.66 \% \\
(9)\end{array}$} \\
\hline Conditions & $\begin{array}{c}18.18 \% \\
(2)\end{array}$ & $\begin{array}{c}0 \% \\
(4)\end{array}$ & $\begin{array}{c}13.40 \% \\
(6)\end{array}$ & $\begin{array}{c}2.63 \% \\
(8)\end{array}$ & \\
\hline
\end{tabular}

* Ranking from 1 through 9 , with 1 being the most innovative.

Table 6 shows that on average physicians attribute more innovativeness to our sample of 20 NMEs than payers. This is implied by the positive difference between the physician and payer innovativeness scores. Table 6 compares the standardized mean physician score to the mean payer score for each drug. Because two different scales were used for the physician (1-4) and payer (1-9) innovativeness scores, the scores had to be standardized by converting the scores into percentages. We used the Spearman rank correlation coefficient, a non-parametric statistic, to correlate the average physician and payer scores per drug. Coefficients of rank correlation measure the extent of similarity between any two groups of scores. If rankings are identical, the coefficient is 1.0. For the physician and payer innovativeness scores per drug, we calculated a Spearman correlation of $r=0.1509$ $(p=0.5359)$. This implies a weak positive correlation between the physician and payer rankings. However, using the Wilcoxon signed-rank test, we found a statistically significant difference between the innovativeness scores: $r=0.0809$ $(p=0.0737)$. This result implies a difference in the degree to which physicians and payers rank drugs as more or less innovative. Specifically, physicians rank drugs as more innovative than payers.

Table 7 reports for each drug the mean, maximum, and minimum number of months between marketing approval and first prescription by a physician. The average of 33 months between approval and first prescription shows it is taking a long time for innovations to get diffused. After having removed the outlier Temodar, ${ }^{\circledR}$ we calculated a statistically significant Spearman rank correlation coefficient of $\mathrm{r}=0.2037(\mathrm{p}=0.04029)$.

Recall, a lower innovativeness score means a drug is viewed as more innovative. Therefore, a positive correlation implies a negative relationship between innovativeness score and time to prescription. In other words, the more innovative a drug, the faster it diffuses.

Table 6. Mean Innovative Score of Physicians and Payer*

\begin{tabular}{|c|c|c|c|}
\hline $\begin{array}{l}\text { Trade } \\
\text { Name }\end{array}$ & $\begin{array}{c}\text { Physician } \\
\text { Mean } \\
\text { Score }\end{array}$ & $\begin{array}{l}\text { Payer } \\
\text { Mean } \\
\text { Score }\end{array}$ & $\begin{array}{l}\text { Difference } \\
\text { (Payer - } \\
\text { Physician)** }\end{array}$ \\
\hline Gleevec $^{\circledR}$ & $\begin{array}{c}0.087 \\
\text { (most innovative) }\end{array}$ & 0.483 & 0.396 \\
\hline Lantus $^{\circledR}$ & 0.133 & $\begin{array}{c}0.210 \\
\text { (most innovative) }\end{array}$ & 0.076 \\
\hline Zetia $^{\circledR}$ & 0.136 & 0.324 & 0.187 \\
\hline Fuzeon $^{\circledR}$ & 0.160 & 0.506 & 0.346 \\
\hline Temodar $^{\mathbb{B}}$ & 0.160 & 0.250 & 0.090 \\
\hline Strattera ${ }^{\circledR}$ & 0.247 & 0.415 & 0.167 \\
\hline $\operatorname{Actos}^{\circledR}$ & 0.270 & 0.261 & -0.009 \\
\hline Lumigan $^{\circledR}$ & 0.273 & 0.290 & 0.016 \\
\hline Abilify ${ }^{\mathbb{B}}$ & 0.276 & 0.313 & 0.036 \\
\hline Avandia $^{\circledR}$ & 0.293 & 0.261 & -0.032 \\
\hline Cymbalta $^{\circledR}$ & 0.307 & 0.279 & -0.028 \\
\hline Reyataz $^{\circledR}$ & 0.310 & 0.268 & -0.043 \\
\hline Viread $^{\circledR}$ & 0.310 & 0.250 & -0.060 \\
\hline Kaletra $^{\circledR}$ & 0.323 & 0.273 & -0.051 \\
\hline Trileptal $^{\circledR}$ & 0.363 & 0.279 & -0.085 \\
\hline Crestor $^{\circledR}$ & 0.430 & 0.420 & -0.010 \\
\hline Protonix $^{\circledR}$ & 0.480 & 0.471 & -0.001 \\
\hline Mobic $^{\circledR}$ & 0.490 & $0.199 * * *$ & -0.291 \\
\hline Aciphex ${ }^{\circledR}$ & $\begin{array}{c}0.597 \\
\text { (least innovative) }\end{array}$ & $\begin{array}{c}0.728 \\
\text { (least innovative) }\end{array}$ & 0.131 \\
\hline
\end{tabular}

* Note that the mean innovativeness score is only a reflection of physicians who are familiar with the drug.

** A positive difference implies that physicians rank the product as more innovative than the payers.

*** Mobic ${ }^{B}$ is now available in generic form and is placed on the lowest tier of every formulary. This skews its innovativeness score.

Table 8 shows the percentage of prescriptions written for each drug for the disease the drug targets, as reported by survey respondents. Here, if we remove Temodar ${ }^{\mathrm{B}}$ (outlier), the Spearman rank correlation coefficient is: $\mathrm{r}=-0.3089$, $\mathrm{p}=0.1982$. Since a lower innovativeness score means a drug is viewed as more innovative, a negative correlation implies a positive relationship between innovativeness score and market share. In other words, the more innovative a drug the higher the market share.

We do not have a definitive answer as to why on average drugs are taking such a long time to diffuse. Part of the explanation may be delays between FDA approval and market launch. Other factors include sluggish uptake on the part of physicians, but also delays instituted by payers. The literature is reporting that during the time it takes for payers to carry out technology assessments in-house or conduct metaanalyses of available data, payers may institute delays in 
Table 7. Time from Approval to First Prescription by Physician

\begin{tabular}{|c|c|c|c|}
\hline Trade Name & $\begin{array}{l}\text { Mean \# of Months from Ap- } \\
\text { proval to First Prescription }\end{array}$ & $\begin{array}{l}\text { Minimum \# of Months from } \\
\text { Approval to First Prescription }\end{array}$ & $\begin{array}{l}\text { Maximum \# of Months from } \\
\text { Approval to First Prescription }\end{array}$ \\
\hline Fuzeon & 12.10 & 0.07 & 22.14 \\
\hline Cymbalta & 17.21 & 0.39 & 36.37 \\
\hline Reyataz & 20.35 & 8.84 & 36.83 \\
\hline Crestor & 21.22 & 2.10 & 48.10 \\
\hline Strattera & 24.31 & 1.64 & 51.58 \\
\hline Zetia & 25.07 & 0.69 & 54.64 \\
\hline Gleevec & 27.85 & 8.21 & 50.17 \\
\hline Abilify & 28.35 & 2.00 & 51.02 \\
\hline Zelnorm & 28.43 & 5.75 & 60.71 \\
\hline Lantus & 29.65 & 1.84 & 63.84 \\
\hline Lumigan & 38.06 & 2.99 & 76.98 \\
\hline Viread & 41.44 & 5.62 & 55.62 \\
\hline Kaletra & 41.78 & 5.03 & 72.97 \\
\hline Protonix & 42.77 & 3.38 & 88.38 \\
\hline Actos & 47.03 & 2.04 & 90.05 \\
\hline Aciphex & 47.03 & 4.90 & 92.85 \\
\hline Mobic & 47.39 & 2.07 & 84.04 \\
\hline Trileptal & 48.61 & 7.03 & 80.03 \\
\hline Avandia & 48.77 & 7.72 & 93.67 \\
\hline Temodar & $83.12(\mathrm{n}=1)$ & - & - \\
\hline Average of 19 drugs* & 33.55 & & \\
\hline
\end{tabular}

*We excluded Temodar ${ }^{\mathbb{R}}$.

reimbursement, ranging from 6 to 12 months following marketing approval [55].

Fig. (7) below represents an approximate transposition of the diffusion data onto a diffusion S-curve analogous to Fig. (1). The S-curve in Fig. (7) is flatter and more drawn out than in Fig. (1), and does not include the experimental period $t_{0}-t_{L}$.. In Fig. (7), $t_{C}$ is 20 months and corresponds to the point of inflection where a critical mass is met and sales start to surge, $t_{\mathrm{AVG}}$ is 33 months and equals the average number of months it takes for physicians to prescribe a drug following marketing approval. It also roughly corresponds to the point at which sales peak.

About $20 \%$ of physicians are innovators or early adopters in that they prescribe drugs prior to point $t_{C}$. Another $40 \%$ fit into the early majority category in that they first prescribe between $t_{C}$ and $t_{A V G}$, while still another $40 \%$ are late majority adopters or laggards who first prescribe after $t_{\mathrm{AVG}}$ has been reached. We should note that physicians are not consistent across all drugs in terms of their time from approval to first prescription. Some may be early adopters for one drug, while being laggards for others.

\subsection{Study Limitations}

Let us note several study limitations. First, we acknowledge the complexity of the questions we posed survey respondents. It may be difficult for physicians to rank alternative treatments because of differences in mortality, complica- tions, side effects, relief of symptoms, and functional improvements that must be considered simultaneously. Second, there may be some recall bias in our physician survey in that the way each survey respondent has answered questions may be affected not just by the correct answer, but also by the respondent's memory. Third, our case study results are not generalizable to the universe of NMEs, owing to the small sample size, not only of NMEs, but also payers. Nor are our findings regarding the physician survey generalizable to the larger population of physicians. Fourth, we recognize that the self-reported innovativeness scores we derived from physicians are proxies that do not take into account the role that detailing may have played in influencing a physician's view of a drug's innovativeness. In this respect, we may have underrepresented the drug industry's influence on physicians' perception of innovativeness. Fifth, our case study did not explicitly examine the questions of how the T2 transfer and adoption of knowledge takes place, nor the relationship between the innovativeness proxies for each drug and health outcomes associated with the respective drugs. These are important questions for future research.

\section{DISCUSSION AND POLICY IMPLICATIONS}

We identified five main stakeholders involved in the translational process of innovation diffusion. These include the biopharmaceutical industry, drug regulatory agencies, physicians, patients, and payers. The role of patients and 
Table 8. Market Share

\begin{tabular}{|c|c|}
\hline Trade Name & Mean \% Market Share \\
\hline Temodar $^{\circledR}$ & $52.5 \%$ \\
\hline Gleevec $^{\circledR}$ & $45.5 \%$ \\
\hline Lantus $^{\circledR}$ & $35.1 \%$ \\
\hline Protonix $^{\circledR}$ & $31.6 \%$ \\
\hline $\operatorname{Actos}^{\circledR}$ & $28.8 \%$ \\
\hline Viread $^{\circledR}$ & $27.6 \%$ \\
\hline Strattera ${ }^{\circledR}$ & $25.2 \%$ \\
\hline Zetia $^{\circledR}$ & $24.8 \%$ \\
\hline Avandia $^{\circledR}$ & $23.2 \%$ \\
\hline Crestor $^{\circledR}$ & $21.8 \%$ \\
\hline Zelnorm $^{\circledR}$ & $21.0 \%$ \\
\hline Kaletra $^{\circledR}$ & $19.4 \%$ \\
\hline Abilify ${ }^{\circledR}$ & $18.4 \%$ \\
\hline Aciphex $^{\circledR}$ & $16.1 \%$ \\
\hline Mobic $^{\circledR}$ & $15.2 \%$ \\
\hline Cymbalta $^{\circledR}$ & $14.3 \%$ \\
\hline Trileptal $^{\circledR}$ & $13.8 \%$ \\
\hline Reyataz $^{\circledR}$ & $13.6 \%$ \\
\hline Lumigan $^{(B)}$ & $13.3 \%$ \\
\hline Fuzeon $^{\circledR}$ & $5.0 \%$ \\
\hline
\end{tabular}

pharmaceutical firms in determining physicians' prescribing patterns has diminished somewhat, while payers increase their influence. Payers directly affect prescribing decisions through the use of formularies, and indirectly by funding evidence-based continuing medical education activities. Our findings suggest that the more innovative a drug is perceived by payers and physicians the higher the market share. Nevertheless, we found a gap in the perception of innovativeness between physicians and payers, with physicians attributing more innovativeness to drugs than payers. Furthermore, it is taking a long time for innovations to get diffused, on average, 33 months for our sample. Also, there is significant variation across physicians, with some physicians reporting having prescribed certain drugs almost immediately following launch, while others report prescribing drugs up to eight years following launch.

Hence, formulary management appears to be a significant emerging T2 barrier [56-58]. Consider the following illustrations:

i. Suppose payers are considering whether to reimburse an off-label indication for an approved drug. Some payers may not consider themselves obligated to cover unproven therapies when doing so would undercut their ability to reimburse proven therapies (prove first argument).

ii. Suppose payers are considering whether to reimburse a male pattern baldness treatment that serves less important health needs than other treatments. Some payers may not consider themselves obligated to cover "lifestyle" medications when doing so would undercut their ability to cover treatments targeting more serious health needs (lifestyle argument). Lifestyle drugs are generally considered those intended to treat diseases or conditions that result from a person's lifestyle choices, or are intended to be used to address a problem that is not considered medically necessary to remedy.

iii. Suppose payers are considering whether to reimburse a drug that is less cost-effective than other drugs in its therapeutic class. Some payers may not consider themselves obligated to cover less cost-effective medications in a therapeutic class (cost-effectiveness argument).

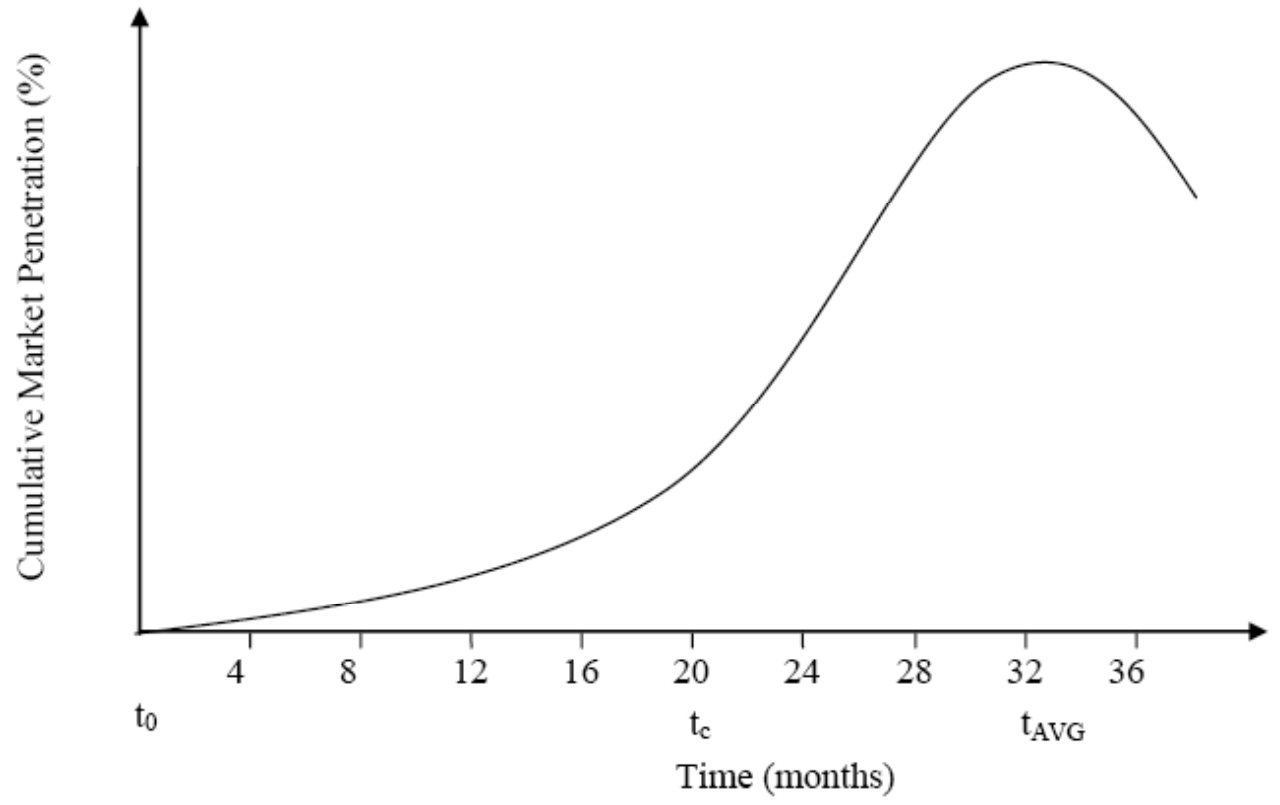

Fig. (6). Transposed Diffusion S-Curve. 
iv. Suppose payers are considering whether to reimburse an expensive, relatively cost-ineffective specialty drug; e.g., a lifesaving biotechnology anti-neoplastic. Some payers may consider themselves obligated to cover any lifesaving treatment, irrespective of costeffectiveness (rule of rescue argument). Rule of rescue is an ethical imperative to save individual lives even when resources may be more efficiently used to prevent deaths in the larger population.

i) Some insurers argue that when a drug is used for an unapproved indication, the use is experimental and therefore should be excluded from coverage [59]. However, off-label uses of approved drugs are considered a vital weapon in the clinician's arsenal. This holds true especially for anti-cancer care where approximately $50 \%$ of chemotherapy regimens are off-label [60]. In 1993, Congress passed a law requiring Medicare to cover off-label drugs used in cancer treatment when the use is supported by a citation in at least one authoritative drug compendium, or in two or more peerreviewed articles published in respected medical journals. One of the drugs in our sample, Temodar, ${ }^{\circledR}$ is an antineoplastic, to which the above law applies. Several other drugs from our sample, most notably Abilify ${ }^{\circledR}$ and Cymbalta, ${ }^{\circledR}$ have multiple off-label uses which have gained entry into nationally recognized compendia as recommended indications. Guidelines are needed on off-label coverage of these drugs as well, specifically, with respect to which compendia would qualify as a sound basis for reimbursement.

ii) Plans often exclude coverage of lifestyle medications, or impose relatively high cost sharing, invoking the principle that the lesser the severity of the disease being targeted by a drug, the more individuals should pay themselves for treatment [61]. None of the drugs in our sample of 20 NMEs are considered lifestyle drugs per sé. But, payers appear to be widening the definition of "lifestyle" to include a broad range of disease categories, spanning the spectrum from erectile dysfunction to birth control to smoking cessation to heartburn. We see that close to $50 \%$ of the payers in our sample do not cover two drugs in our sample, Aciphex ${ }^{\circledR}$ or Protonix, ${ }^{\circledR}$ which are used for heartburn. And, of the payers covering Aciphex ${ }^{\circledR}$ and Protonix, ${ }^{\circledR}$ nearly $50 \%$ apply conditions of reimbursement. This is consistent with a general trend in the formulary management of proton pump inhibitors [62]. From both a payer and policymaker perspective, practical guidelines are needed that delineate lifestyle from non-lifestyle indications and medications in medically appropriate ways.

iii) As was said above, there is a trend among payers towards the use of cost-effectiveness analyses to inform coverage decisions on drugs, particularly those in crowded therapeutic classes. Statins are one such crowded therapeutic class. For example, Crestor ${ }^{\circledR}$ is one of eight statins [63]. Across our sample of 20 payers we see wide variation with respect to its coverage, with most imposing relatively high cost sharing and restrictions. Payer policies on therapeutically interchangeable drugs may make sense from a purely economic perspective, but may be harmful to patients who respond well to one drug in a particular therapeutic class and not to another. From a payer and policymaker perspective, practical guidelines are needed that ensure a flexible ap- proach to the use of cost-effectiveness analyses in determining reimbursement.

iv) Payers tend to cover drugs targeting life-threatening diseases, yet vary widely in terms of cost sharing and conditions of reimbursement. Across payers, we observe that all cover lifesaving treatments, such as Fuzeon ${ }^{\circledR}$ and Gleevec. ${ }^{\circledR}$ This said, many impose comparatively onerous cost sharing as well as strict conditions of reimbursement on these drugs. To ensure widespread, equitable access to such lifesaving treatments, legislation is needed to reduce the cost burden of those who cannot afford the co-payments being levied upon them by payers, nor bear the additional conditions imposed on their reimbursement.

The 2007 reauthorization of the FDAMA Act is resulting in changes in FDA regulations, specifically, more stringent safety standards, mandates regarding the size and number of clinical trials, and new labeling requirements. These regulatory changes may make it harder for drugs to cross the safety, efficacy, and quality hurdles. But while the FDA is ratcheting up standards, a fourth hurdle relevant to market access, is emerging as a key T2 barrier [64-66].

Though all stakeholders agree that technological innovation in the health sector has significant health benefits, payers and policymakers think we can do a better job fine-tuning and streamlining the translational process, which implies providing positive incentives for the adoption and diffusion of new drugs that are more effective and disincentives for the adoption and diffusion of new drugs that are less effective. Accordingly, payers and policymakers are cautiously embarking on a path towards the use of comparative effectiveness to assess the value (i.e., innovativeness) and optimal diffusion of new drugs. Although in its infancy stage, such assessments are becoming more commonplace. To illustrate, DERP formally assessed 19 out of the 20 drugs in our sample. The Tufts Center for the Evaluation for Value and Risk in Health has seven of the 20 drugs in its cost-effectiveness assessment registry [67]. And, six of the 20 drugs in our sample were formally assessed by AHRQ [68]. These systematic reviews of drugs and drug classes have helped clarify the evidence base, but until now have often not yielded actionable advice to payers and clinicians on reimbursement and utilization. Moreover, they have also purposively left cost out of the equation, for fear of backlash coming from patient advocacy groups and the drug industry.

Comparative effectiveness as a policy tool is gaining traction in Congress. Draft legislation calls for expansion of comparativeness effectiveness research through the establishment of an independent research center that would give comparative effectiveness data a more explicit and systematic role in Medicare Part D formulary reviews carried out by CMS. Support for establishment of a federally sponsored center is also coming from several large payers.

Drug manufacturers often lament the imposition of a fourth hurdle because it may limit access to new drugs, while dampening incentives for innovation. The reality is that comparative effectiveness analyses are here to stay as a tool to guide reimbursement and prescribing decisions [69]. Drug makers that recognize the strategic value of comparative effectiveness analyses and effectively integrate them into 
their R\&D decision-making processes will likely acquire competitive advantages.

There are many unresolved questions, such as the politically contentious one of whether to include cost in comparative effectiveness studies. But, besides inclusion of cost, the overarching problem is how to implement an appropriate set of incentives that would stem from comparative effectiveness assessments without harming long-term biopharmaceutical innovation. In other words, the emerging T2 challenge is translating the syntheses of evidence that have been produced and are forthcoming into practical recommendations for payers and physicians that balance affordability and longterm innovation. In some cases, these recommendations may lead to payer restrictions. And although payer restrictions, whether in the form of denials of coverage or conditions of reimbursement, may make good economic sense, they can reach back to negatively impact innovation by adding time and cost to the drug development process. The costs of data collection would augment already high drug development costs. Furthermore, comparative effectiveness evaluations could result in delays in reimbursement while the analyses are being carried out. Recent experience in the UK suggests that if comparative (cost)-effectiveness studies for new drugs are carried out early (e.g., shortly before or after launch) they may run into serious methodological problems regarding the reliability of extrapolations and long-term projections. While if they are deferred until a later stage, the result may be what is termed "NICE blight," or reluctance on the part of payers and physicians to reimburse or prescribe, respectively, before guidance has been issued.

One forward-looking way of balancing payer, policymaker, and drug sponsor concerns is Medicare's coverage with evidence development policy, which currently applies to a small number of Part B drugs, among other medical technologies. CED allows for Medicare reimbursement immediately following approval for drugs that appear promising, but where the data are not unequivocally positive, until the drug sponsor submits the data necessary to determine coverage [70]. During the period of data collection, which could have a time horizon of three to five years, Medicare covers virtually all costs associated with drugs that fall under the policy. At the end of the three to five year period, Medicare policymakers intend to revisit coverage decisions.

In spite of technology assessment often being considered a challenge, even a threat, to the biopharmaceutical industry, five examples of Medicare national coverage determinations, which followed a CED format, illustrate how technology assessment actually facilitated access. First, clinical- and cost-effectiveness estimates regarding hemodialysis in endstage renal patients projected relatively low cost per year of life extension, which ultimately influenced the decision by Congress to fund coverage for all Medicare beneficiaries [71]. Second, studies of third-generation cephalosporins for hospital-acquired pneumonia demonstrated cost savings when compared to standard multiple-drug regimens [72]. Third, recently completed studies on the expansion of indications for the use of PET-scans suggested their costeffectiveness in some indications, but not all [73]. Fourth, the decision to cover implantable cardioverter defibrillators under the proviso of evidence development has provided broad access to a potentially life-saving treatment. Fifth,
CED policy has enabled conditional reimbursement of offlabel uses of chemotherapy drugs for colorectal cancer.

By avoiding outright denials or overly restrictive limits on coverage, CED may constitute a way of closing the gap that exists between physician and payer perceptions of innovativeness with regard to certain new drugs. For example, in our case study, we see that Fuzeon ${ }^{\mathbb{B}}$ and Gleevec ${ }^{\mathbb{B}}$ are both considered much more innovative by physicians than payers. Payers have imposed conditions of reimbursement and significant cost sharing on these two drugs, which appears at odds with physicians' characterizations of their innovativeness. Specifically in cases in which there is a large degree of uncertainty or the economic (i.e., fiscal) impact is especially high, coverage could be made subject to CED policy.

In certain instances, particularly when there is a very large degree of uncertainty, augmenting CED with a risksharing arrangement could help to facilitate broader access to drugs while collecting data on a drug's comparative effectiveness in order to promote efficient use of resources. Comparative effectiveness analyses then lay an empirical basis for perceptions that may vindicate or reject either set of perceptions. Here, payers and manufacturers share the potential cost of a new drug or off-label indication. For example, in Britain, Johnson \& Johnson and NICE announced a costsharing arrangement in which the drug sponsor will rebate the cost of the cancer drug Velcade ${ }^{\circledR}$ when patients have a minimal response to the drug. Johnson \& Johnson offered the risk-sharing scheme as a way to ensure broader access to the drug while collecting additional data on its costeffectiveness [74].

\section{ABREVIATIONS}

$$
\begin{aligned}
& \text { AHRQ }=\text { Agency for Healthcare Research and Quality } \\
& \text { AIDS }=\text { Acquired Immune Deficiency Syndrome } \\
& \text { BCBS }=\text { Blue Cross Blue Shield } \\
& \text { CEA }=\text { Cost-Effectiveness Analysis } \\
& \text { CMS }=\text { Center for Medicare and Medicaid Services } \\
& \text { DERP }=\text { Drug Effectiveness Review Project } \\
& \text { EPC }=\text { Evidence-Based Center (affiliated with AHRQ) } \\
& \text { FDA }=\text { Food and Drug Administration } \\
& \text { IND }=\text { Investigational New Drug } \\
& \text { MMA }=\text { Medicare Modernization } \\
& \text { NDA }=\text { New Drug Application } \\
& \text { NICE }=\text { National Institute for Clinical Excellence } \\
& \text { NIH }=\text { National Institutes of Health } \\
& \text { NME }=\text { New Molecular Entity } \\
& \text { PET }=\text { Positron Emission Tomography } \\
& \text { PDP }=\text { Prescription Drug Plan } \\
& \text { R\&D }=\text { Research and Development } \\
& \text { TEC }=\text { Technology Evaluation Center }
\end{aligned}
$$

\section{REFERENCES}

[1] Rogers, E. The Diffusion of Innovations, $5^{\text {th }}$ ed. New York Free Press: New York, 2003. 
[2] Attridge, J. Tanaka Business School, Imperial College London: Innovation Models and their Application to the Pharmaceutical Sector. http://www3.imperial.ac.uk/portal/pls/portallive/docs/1/729 0711.pdf (accessed May 2, 2007)

[3] Huber, M.; Orosz, E. Health expenditure trends in OECD countries, 1990 - 2001. Health Care Financ. Rev., 2003, 25, 1-15.

[4] Meyer J. New Directions for Policy: Assessing the Impact of Biopharmaceutical Innovation: A Comprehensive Framework. http://www.npcnow.org/resources/PDFs/meyerfinal.pdf (accessed March 22, 2007)

[5] Cain, M., Mittman, R. Diffusion of Innovation in Health Care, Institute for the Future: Oakland, CA, 2002.

[6] Woolf, S. The meaning of translational research and why it matters. JAMA, 2008, 299, 211-213.

[7] Here, adoption refers to the stage in which a technology is selected for use by an individual or an organization. Diffusion refers to the stage in which the technology spreads to general use and application.

[8] Congressional Budget Office: Research and Development in the Biopharmaceutical Industry. http://www.cbo.gov/ftpdocs/76xx/doc 7615/10-02-DrugR-D.pdf (accessed April 25, 2007).

[9] Alternatively, a drug that has been approved for specific indication(s) may be used off-label for other, as yet, unapproved indications.

[10] National Health Policy Forum (Issue Brief No. 749), Strongin, R.: The ABCs of PBMs. http://www.nhpf.org/pdfs_ib/IB749_ABCs ofPBMs_10-27-99.pdf (accessed June 4, 2007).

[11] Allery, L.; Owen, P.; Robling, M. Why general practitioners and consultants change their clinical practice: a critical incident study. $B M J, 1997,314,870-874$.

[12] Astra Zeneca: A Guide to Cancer Drug Development and Regulation. http://www.cancerline.com/gUserFiles/Regulatory_Guide 72 dpi.pdf (accessed June 4, 2007).

[13] Breast Cancer Action: Politics of Breast Cancer. http://www.bca ction.org/Pages/GetInformed/FAQPolitics.html (accessed June 4, 2007).

[14] Cockburn, I.; Henderson, R. Publicly funded science and the productivity of the pharmaceutical industry. In Innovation Policy and the Economy (Volume 1); Jaffe, A.; Lerner, J.; Stern, S., Eds.; MIT Press for the National Bureau of Economic Research, Cambridge, Massachusetts, 2001; pp. 1-34.

[15] Neumann, P., Weinstein, M. The diffusion of new technology: costs and benefits to health care. In The Changing Economics of Medical Technology; Gelijns, A.; Halm, E.; Eds.; Institute of Medicine, National Academy of Science, Washington DC, 1991; pp. 2134.

[16] Gelijns, A.; Rosenberg, N. The dynamics of technological change in medication. Health Affairs, 1994, 13, 28-46.

[17] Milne, C.; Reichert, J. Public and Private Sector Contributions to the Discovery and Development of "Impact" Drugs. Am. J. Therapeut., 2002, 9, 543-555.

[18] Gelijns, A., Graff Zivin, J., Nelson, R. Uncertainty and technological change in medication. J. Health Politics, Policy, and Law, 2001, 26, 216-245.

[19] FDA Opens Baycol ${ }^{\circledR}$ Probe: Agency Feeling the Heat after Vioxx ${ }^{\circledR}$ Withdrawal. http://www.consumeraffairs.com/news04/vioxxbayco 1 fda.html. (accessed April 10, 2007).

[20] Lichtenberg, F. Benefits and costs of newer drugs: an update. NBER Working Paper, 2002, W8996.

[21] Centre for the New Europe: Economic Evaluation and the Funding of Biopharmaceutical Products. http://www.cnehealth.org/pubs/12 0001_Nice_treaty.pdf. (accessed June 1, 2007).

[22] Kaiser Family Foundation: Medicare Factsheet. http://www.kff.org. (accessed June 4, 2007).

[23] United States Senate Committee on Finance: Grassley, Baucus Sponsor Bill for Research on Effectiveness and Safety of Medical Treatments. http://www.senate.gov/ finance/press/Gpress/2005/prg 091806.pdf. (accessed April 19, 2007).

[24] Tucker, P.; Nash, D. Formulary management of anti-ulcer drugs: economic considerations. Pharmacoeconomics, 1994, 5, 313-334.

[25] Stolk, E., Busschbach, J. Cost utility of sildenafil compared to papaverine-phentolamine injections. BMJ, 2000, 320, 1165-1170.

[26] Neumann, P.; Sandberg, E.; Bell, C.; Stone, P.; Chapman, R. Are biopharmaceuticals cost-effective? A review of the evidence. Health Affairs, 2000, 19, 92-109.
[27] Chilcott, J.; McCabe, C.; Tappenden, P.; O’Hagan, A.; Cooper, N.; Abrams, K.; Claxton, K. Modelling the cost effectiveness of interferon beta and glatiramer acetate in the management of multiple sclerosis. BMJ, 2003, 326, 522-527.

[28] Cohen, J.; Cabanilla, L.; Sosnov, J. The role of follow-ons on the WHO essential drug list. J. Clin. Pharm. Therapeut., 2006, 31 , 585-592.

[29] NICHM Foundation: Changing Patterns of Pharmaceutical Innovation. http://www.nihcm.org/innovations/pdf, (accessed April 1, 2008)

[30] Wastila, L., Ulcickas, J., Lasagna, L. The World Health Organization's essential drug list. The significance of me-too and follow-on research. J. Clin. Res. Drug Devel., 1989, 3, 105-115.

[31] Nelson, R., Winter, S. An Evolutionary Theory of Economic Change. Harvard University Press: Cambridge, Massachusetts, 1982

[32] DiMasi, J.; Paquette, C. The economics of follow-on drug research and development. Pharmacoeconomics, 2004, 22 (Suppl.), 1-14.

[33] United States Office of Technology Assessment: Pharmaceutical R\&D: Costs, risks, and rewards. OTA-H-522, February 1993.

[34] Tufts Center for the Study of Drug Development: Follow-on Drugs and Indications Play Key Role for World Health Organization. Impact Report, July/August 2007.

[35] Food and Drug Administration: Oncology Tools: Fast Track, Priority Review, and Accelerated Approval. http://www.accessdata. fda.gov/scripts/cder/onctools/accel.cfm, (accessed April 19, 2007)

[36] Coleman, J.; Katz, E.; Henzel, E. The diffusion of an innovation among physicians. Sociometry, 1957, 14, 253-270.

[37] DiMasi, J.; Caglarcan, E.; Wood-Armany, M. The emerging role of pharmacoeconomics in the R\&D decision-making process. Pharmacoeconomics, 2001, 19, 753-66.

[38] Blue Cross Blue Shield Association: Technology Evaluation Center. http://www.bcbs.com/tec/index.html, (accessed June 5, 2007)

[39] Neumann, P.; Rosen, A.; Weinstein, M. Medicare and costeffectiveness analysis. N. Engl. J. Med., 2005, 353, 1516-1522.

[40] Cohen, J.; Cairns, C.; Paquette, C.; Faden, L. Comparing patient access to pharmaceuticals in the UK and US. Appl. Health Econom. Health Policy, 2006, 5, 177-187.

[41] Orszag, P.; Ellis, P. Addressing rising health care costs - a view from the Congressional Budget Office. N. Engl. J. Med., 2007, 357, 1885-1887.

[42] Congressional Budget Office: Research and Development in the Pharmaceutical Industry. http://www.cbo.gov/ftpdocs/76xx/doc761 5/10-02-DrugR-D.pdf, (accessed June 5, 2007).

[43] Carpenter, D. The political economy of FDA drug review: processing, politics, and lessons for policy. Health Affairs, 2004, 23, 5263.

[44] Marcus, A. Cancer patients gain say in drug approvals. Wall St. J., February 13, 2007, p.D1.

[45] Nelson, R. Issues and suggestions for the study of industrial organizations in a regime of rapid technical change. In Policy Issues and Research Opportunities in Industrial Organization, Ed.; Fuchs, V.; Columbia University Press: New York, 1972, pp. 34-58.

[46] Employee Benefit Research Institute: Prescription Drugs: Recent Trends in Utilization, Expenditures, and Coverage. http://www.eb ri.org/pdf/briefspdf/0104ib.pdf, (accessed August 27, 2007).

[47] Neumann, P. Evidence-based and value-based formulary guidelines. Health Affairs, 2004, 23, 124-134.

[48] Colmenero, F.; Sullivan, S.; Palmer, J.; Brauer, C.; Bungay, B.; Watkins, J.; Neumann, P. Quality of clinical and economic evidence in dossier formulary submissions. Am. J. Manag. Care, 2007, 13, 401-407.

[49] Ubel, P. How stable are people's preferences for giving priority to severely ill patients? Soc. Sci. Med., 1999, 49, 895-903.

[50] Drug Trends. http://www.nationaltechexam.org/pdf/top $200 \mathrm{drug}$ list05.pdf, (accessed August 27, 2007).

[51] Kaiser Family Foundation: Hoadley, J.; Hargrave, E.; Cubanski, J.; Neuman, T. An In-Depth Examination of Formularies and other Features of Medicare Drug Plans. http://www.kff.org/medicare/ 7489.cfm, (accessed September 25, 2007).

[52] To view our survey instrument, see http://www.illuminainteractive.com/tuftssurveys/innovation/.

[53] Fuchs, V.; Sox, H. Clinicians' views of the relative importance of thirty medical innovations. Health Affairs, 2001, 20, 30-42.

[54] Institute of Medicine: Tunis, S., Korn, A., Ommaya, A. Eds; Role of Purchasers and Payers in the Clinical Research Enterprise 
(workshop summary); National Academy Press: Washington DC, 2002.

[55] Fox, P. Prescription drug benefits: cost management issues for Medicare. Health Care Financ. Rev., 2003, 25, 2-25.

[56] New Directions for Policy: Meyer J. Assessing the Impact of Pharmaceutical Innovation. http://www.npcnow.org/resources/PDF s/meyerfinal.pdf, (accessed November 28, 2006).

[57] Gibson, J.; Martin, D.; Singer, P. Priority setting for new technologies in medication: a transdisciplinary study. BMC Health Serv. Res., 2002, 2, 14-18.

[58] Taylor, R., Drummond, M., Salkeld, G., Sullivan, S. Inclusion of cost effectiveness in licensing requirements of new drugs: The fourth hurdle. BMJ, 2004, 320, 972-975.

[59] Anand, G. Burden of proof: As costs rise, new medicines face pushback. Wall St. J., September 18, 2007, p.D1.

[60] Mortensen, L. Public policy and access to new drugs: the case of cancer chemotherapy. In The Changing Economics of Medical Technology; Gelijns, A.; Halm, E.; Eds.; Institute of Medicine, National Academy of Science, Washington DC, 1991; pp. 53-68.

[61] Lexchin, J. Lifestyle drugs: issues for debate. Can. Med. Assoc. J., 2001, 164, 1449-1451.

[62] Byrne, M.; Murray, F. Formulary management of proton pump inhibitors. Pharmacoeconomics, 1999, 16, 225-246.

[63] Chong, P.; Seeger, J.; Franklin, C. Clinically relevant differences between the statins: implications for therapeutic selection. Am. J. Med., 2001, 111, 390-400.
[64] Weisbrod, B. The health care quadrilemma: an essay on technological change, insurance, quality of care, and cost containment. $J$. Eco. Lit., 1991, 29, 523-552

[65] Huttin, C. Technology policy and cost containment issues: Government challenges in the governance of biobiopharmaceutical innovation. J. Biolaw Bus., 1999, 2, 47-53.

[66] Institute of Medicine: Crossing the Quality Chasm: A New Health System for the $21^{\text {st }}$ Century, National Academy Press; Washington DC, 2001.

[67] See http://research.tufts-nemc.org/cear/default.aspx, (accessed March $5,2008)$

[68] See http://www.ahrq.gov, (accessed March 1, 2008).

[69] Rettig, R. Medical innovation duels cost containment. Health Affairs, 1994, 13, 7-27.

[70] Medicare Payment Advisory Commission: Promoting Greater Efficiency in Medicare. http://www.medpac.gov/documents/Jun 07_EntireReport.pdf, (accessed July 5, 2007).

[71] National Center for Policy Analysis, Rettenmaier, A., Wang, Z. Medicare Prescription Drug Benefit: What Difference Would it Make? Brief Analysis no. 463; 2004.

[72] Owens, R.; Rice, L. Hospital-based strategies for combating resistance. Clin. Inf. Dis., 2006, 42, S173-S181.

[73] Project HOPE Center for Health Affairs: The Impact of Medical Technology on Future Health Care Costs http://www.ahipresearch. org/PDFs/26 FinalRptApp1\&3.pdf, (accessed November 2, 2007).

[74] Neumann, P. Emerging lessons from the drug effectiveness review project. Health Affairs, 2006, web exclusive, W262-W271.

(C) Cohen et al.; Licensee Bentham Open.

This is an open access article licensed under the terms of the Creative Commons Attribution Non-Commercial License (http://creativecommons.org/licenses/by$\mathrm{nc} / 3.0 /$ ) which permits unrestricted, non-commercial use, distribution and reproduction in any medium, provided the work is properly cited. 